\title{
Commentary: The challenging management of coronary artery fistulas
}

\author{
Christoph Haller, MD
}

\footnotetext{
From the Department of Cardiovascular Surgery, The Labatt Family Heart Centre, The Hospital for Sick Children, University of Toronto, Toronto, Ontario, Canada.

Disclosures: Author has nothing to disclose with regard to commercial support.

Received for publication Nov 29, 2018; accepted for publication Nov 29, 2018; available ahead of print Jan 9 , 2019.

Address for reprints: Christoph Haller, MD, Division of Cardiovascular Surgery, The Hospital for Sick Children, 555 University Ave, Toronto, Ontario, Canada, M5G 1X8 (E-mail: christoph.haller@ sickkids.ca).

J Thorac Cardiovasc Surg 2019;157:205-6

$0022-5223 / \$ 36.00$

Copyright (c) 2018 by The American Association for Thoracic Surgery

https://doi.org/10.1016/j.jtcvs.2018.11.117
}

Asymptomatic small coronary artery fistulas are quite common malformations and can be considered normal. ${ }^{1}$ Large fistulas, however, create a significant shunt and can lead to heart failure if left untreated. The incidence of coronary artery to coronary sinus fistulas is very low, and publications on surgical treatment are limited to case reports. ${ }^{2,3}$ This particular subtype is also anatomically challenging, as these fistulas tend to have a very tortuous course and show significant enlargement of the affected vessels. ${ }^{4}$ In this issue of the Journal, Barac and colleagues ${ }^{5}$ present an exceptionally rare case of a coronary artery-to-coronary sinus fistula involving both the right coronary artery and the left circumflex artery. Closure of the coronary fistula had been attempted previously, but the patient represented with increasing sings of heart failure indicating repeat intervention. The common orifice of the fistula at the coronary sinus was suture ligated and additional closure of the respective left and right arterial end of the fistula was performed.

Management of patients with coronary artery fistulas depends on the individual case, and guidelines mandate an interdisciplinary team approach to discuss surgical therapy. ${ }^{6}$ Surprisingly, insufficient closure of fistulas is quite common. Between $6 \%$ and $30 \%$ of cases have been shown to have residual flow after surgical or catheter-based closure, with surgical closure being more reliable. ${ }^{7,8}$ Fortunately, the need for reintervention remains low. It is therefore unusual that the patient developed a recurrent fistula over the course of 11 years. As details on the fistula and the initial procedure performed are not reported, we are left speculating whether it is true recurrence of the previous fistula or subsequent enlargement of undetected smaller fistulous connections after closure of the primary fistula.

Nonetheless, the report nicely delineates that especially cases with complex anatomy and difficult surgical exposure of the fistula and its respective orifices are challenging and should be addressed on cardiopulmonary bypass with cardioplegic arrest. As reported by Barac and colleagues, ${ }^{5}$ cardioplegia application can be compromised in patients with

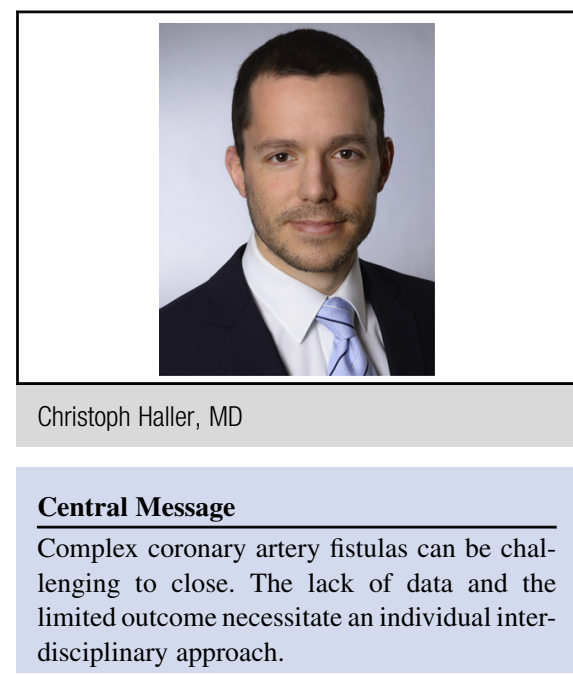

See Article page e203.

large coronary fistulas that result in a runoff bypassing the myocardial capillary bed. Manual closure of the fistulous connection can improve effectiveness. However, direct application of cardioplegia into the fistula orifice has proven to be a valuable alternative.

The good short-term outcome of the reported case should not belittle the associated risks of coronary artery fistula closure. Published series have stressed the important risk of both early and late myocardial infarction and a substantially decreased survival rate in this patient group. ${ }^{8,9}$ It is therefore of great clinical value to report coronary fistula cases in greater detail regarding surgical strategy as well as pre- and postoperative management. Unfortunately, the report by Barac and colleagues ${ }^{5}$ goes little beyond the fact that this rare anatomic malformation can be closed surgically.

\section{References}

1. Haller C, Schlensak C. Congenital anomalies of the coronary arteries and coronary diseases of children and adolescents. In: Ziemer G, Haverich A, eds. Cardiac Sur gery: Operations on the Heart and Great Vessels in Adults and Children. Berlin, Heidelberg: Springer Berlin Heidelberg; 2017:641-61.

2. Yamanaka O, Hobbs RE. Coronary artery anomalies in 126,595 patients undergoing coronary arteriography. Cathet Cardiovasc Diagn. 1990;21:28-40.

3. Levin DC, Fellows KE, Abrams HL. Hemodynamically significant primary anomalies of the coronary arteries. Angiographic aspects. Circulation. 1978;58:25-34.

4. Loukas M, Germain AS, Gabriel A, John A, Tubbs RS, Spicer D. Coronary artery fistula: a review. Cardiovasc Pathol. 2015;24:141-8.

5. Barac YD, Milano CA, Turek JW. Coronary artery arteriovenous malformation. J Thorac Cardiovasc Surg. 2019;157:e203-4.

6. Stout KK, Daniels CJ, Aboulhosn JA, Bozkurt B, Broberg CS, Colman JM, et al 2018 AHA/ACC guideline for the management of adults with congenital heart 
disease. Executive summary: a report of the American College of Cardiology/ American Heart Association task force on clinical practice guidelines. J Am Coll Cardiol. August 10, 2018 [Epub ahead of print].

7. Kiefer TL, Crowley AL, Jaggers J, Harrison JK. Coronary arteriovenous fistulae: the complexity of coronary artery-to-coronary sinus connections. Tex Heart Inst J. 2012;39:218-22.
8. Said SM, Burkhart HM, Schaff HV, Connolly HM, Phillips SD, Suri RM, et al. Late outcome of repair of congenital coronary artery fistulas - a word of caution. J Thorac Cardiovasc Surg. 2013;145:455-60.

9. Valente AM, Lock JE, Gauvreau K, Rodriguez-Huertas E, Joyce C, Armsby L, et al. Predictors of long-term adverse outcomes in patients with congenital coronary artery fistulae. Circ Cardiovasc Interv. 2010;3:134-9. 